\title{
Sustainable Design in Landscape Architecture Education
}

\author{
Tugba Duzenli \\ Department of Landscape Architecture, Karadeniz Technical University \\ PO box 61080, Trabzon, Turkey \\ E-mail: tugbaduzenli@gmail.com
}

\begin{abstract}
Sustainable design process can be achieved by bringing together different disciplines and developing a common product. However, the main decisions to be taken for the product; information and analysis to be determined during the design phase; factors affecting the format; the detailed solutions of the details and design decisions should be made by the designer. For this reason, the designer must synthesize sustainable design and production information for the concept of sustainable design. This is among the learning outcomes that should be gained in design education. For this reason, within the scope of the study, Furniture Design Course which is one of the 3rd semester courses of Karadeniz Technical University, the effects of sustainable urban furniture models and education produced in the fall semester of 2018-2019 were examined.
\end{abstract}

Keywords: Design education, sustainability, reinforcement design, landscape architecture

DOI: $10.7176 / \mathrm{JSTR} / 5-2-21$

\section{Peyzaj Mimarlığı Eğitiminde Sürdürülebilir Donatı Tasarımı}

\begin{abstract}
Özet
Sürdürülebilir tasarım süreci farklı disiplinlerin bir araya gelerek ortak bir ürün geliştirmesi ile sağlanabilir. Ancak ürün için alınacak ana kararlar; tasarım aşamasında saptanacak bilgiler ve analizler; biçime etki eden faktörler; detayların ayrıntılı çözümlerinin sorgulanması ve tasarım kararları tasarımcı tarafından biçime aktarılmalıdır. Bu nedenle tasarımcı, 'sürdürülebilir tasarım' kavramı için sürdürülebilir tasarım ve üretim bilgilerini sentezlenmek zorundadır. Bu da tasarım eğitiminde kazandırılması gereken öğrenim çıktıları arasındadır. Bu nedenle çalışma kapsamında Karadeniz Teknik Üniversitesi 3. Yarıyıl derslerinden olan 'Donatı Tasarımı Dersi' kapsamında 2018-2019 Güz yarıyılında üretilen sürdürülebilir kent donatı maketleri ve eğitime etkileri incelenmiştir.
\end{abstract}

Anahtar Kelimeler: Tasarım eğitimi, sürdürülebilirlik, donatı tasarımı, peyzaj mimarlığı

\section{Giriş}

Tasarım, kendi başına çok kapsamlı bir kavram olduğundan, sürdürülebilirlik ile ele alındığında daha da kapsamlı tanımlamalara ihtiyaç duymaktadır. Tasarım sürecinin öncesinde ve sonrasında ürünlerin zincirleme bir yaşam döngüleri olduğu gözlenir. Bu bağlamda, yaşamın sürdürülebilirliği ve gelecek insan yaşam ortamlarının korunması için hava, su, gıda, barınma vb. öncelikli ve acil konularda güvenli çevre ve ortamların hazırlanması zorunluluğu öngörülmelidir (Şatır, 2015). Sürdürülebilir tasarım yaklaşımı teknoloji-işlevsellik-estetik ve ekonomik olarak tanımlanan mimari tasarım ölçütlerinin doğa-çevre-enerji korunumu ve konfor konuları ile genişleyerek değişmesine neden olmuştur. Böylece enerji tüketiminde önemli bir paya sahip olan yapı tasarımının yeniden tanımlanmasını sağlamıştır (Dikmen, 2011; Dikmen ve Gültekin, 2009). Bu tanımlama kapsamında sürdürülebilir tasarım ölçütleri aşağıda ifade edildiği şekilde sıralanabilir (Bourdeau, 1999; CIB, 1999; WGSC, 2004; Yeang, 1999):

- Yapı kabuğu ve yapı formunun konum, topoğrafya, iklim, manzara, hakim rüzgar vb. içeren fiziksel çevre verilerine uygun biçimlendirilerek enerji verimliliği sağlanması,

- Kaynak korunumu, enerjinin etkin ve verimli kullanılması ve alternatif enerji kullanımının 
yaygınlaştırılması,

- Enerjinin, bakım ve onarım maliyetlerinin, yapıyla ilişkili hastalıkların, atık ve kirliliğin azaltılması ve atıkların değerlendirilmesi,

- Esnek ve değişen koşullara uyum sağlayabilen, uzun kullanım ömrüne sahip yapı tasarımı ile yapılardan beklenilen performans düzeyinin arttırılması,

- Sürdürülebilir, geri dönüştürülebilir ve çevreye duyarlı yapı malzemeleri kullanarak yapı ürünlerinin verimliliğinin ve konforunun, yapı ve bileşenlerinin dayanıklılığının ve esnekliğin attırılması,

- Zararlı ve tehlikeli maddelerden sakınılması ve yapıyla ilgili sağlı ve güvenlik risklerinin en aza indirgenmesi,

- Sağlıklı mekânlar yaratılması ve iç hava kalitesi sağlanması,

- Sunduğu nitelikli ve yaşanabilir çevreler ile kullanıcı memnuniyeti sağlayan mekânların elde edilmesi ve Biyolojik çeşitliliğin korunması ve habitatın korunumu.

- Tüm bu ölçütlerin göz önünde bulundurulması; kullanışl1, kullanıcı ihtiyaçlarını karşılayan, uzun ömürlü ve başarılı tasarım ürünlerinin ortaya çıkmasını sağlar. Bu nedenle kentsel donatı tasarımında sürdürülebilirliği sağlamak oldukça önemlidir. Bundan sonraki kısımda kentsel donatılar hakkında bilgi verilecektir.

\section{Kentsel Donatı Elemanları Tasarımı}

Kenti yaşanabilir ve algılanabilir kılan kentsel donatı elemanlarının her biri kullanıcılar ve kent açısından farklı bir anlama ve öneme sahiptir. Kullanıcılar açısından bu elemanların önemi kullanıcıların kentle kurdukları görsel ve fiziksel ilişkinin öncelikle kentsel donatı elemanları aracılığıyla olması nedeniyledir. Kent açısından ise bu elemanlar bulundukları çevreyi tanımlayan, belirleyen ve özelleştiren nitelikleri nedeniyle önemlidir. Belirli bir düzen içinde ele alınan, bulundukları çevre ile bütünleşerek kentin bir öğesi haline gelen donatı elemanları birbirleri ile kurdukları dil birlikteliği aracılığı ile bir kentin kimliğinin oluşmasına katkı koyan en önemli araçlardandır. Bu nedenle kentsel donatı elemanlarının birer tasarım ürünü olarak ele alınmalarını sağlayacak, birbirleri ve yer aldıkları kentsel mekânlar ile doğru ilişkiler kurmalarını olanaklı kılacak bazı yaklaşımlara gerek duyulmaktadır (Güremen, 2011; Düzenli vd.2018a).

Sosyal, kültürel ve ekonomik özellikler gösteren kentsel donatı elemanları, öncelikle kentlilerin farklı gereksinimlerine cevap verecek işlevlere uygun bir biçimde tasarlanmak zorundadır. Donatı elemanları kentsel mekânın yerine, büyüklüğüne ve anlamına uyumlu olmalı, içinde yer aldığı çevrenin karakterini yansıtmalıdır. Kentsel donatı elemanları aynı zamanda kullanıcılara psikolojik rahatlık sağlamaları açısından da ele alınmalıdır. Kentsel donatı elemanlarının kullanıcıların farklı gereksinimlerinin ötesinde toplumun kültürel, sosyal ve ideolojik yapısına referansla düşünülmeleri gerekmektedir (Aydoğdu, 2017; Düzenli vd., 2018b).

Bulunduğu mekâna uygun olarak tasarlanan donatı takımları aynı zamanda işlevsel, kimlikli, estetik, sürdürülebilir ve uygulanabilir özellikte olmalıdır. İşlevsel açıdan bir kent mobilyası kullanıcısına uygun olarak bileşenlerinin neler olduğu, bu bileşenlerin sistemin hangi parçasını oluşturduğu ve sistemi ayakta tutan işlevlerin neler olduğu belirlenmelidir (Ertaş, 2007; Kurdoğlu vd., 2018; Düzenli vd., 2017; Düzenli vd., 2018c). Donatılar sadece işlevsel ve fonksiyonel amaçlı değil aynı zamanda estetik kaygı taşıyan çizgi ve biçimlerden oluşmalı, bulunduğu ortama kimlik de kazandırmalıdır (Kumbaracıbaşı, 1991)

Tasarım sadece fiziksel olarak bir şeyleri şekillendirmek değildir ya da sistem ile ilişkili olan profesyonel uygulamalar değildir. Tasarım insanların, ihtiyaç ve tercihleri ile ortaya çıkan (Prudhomme et al. 2003, Clarkson et al. 2004, Siu 2004), hatta insan davranışlarını şekillendiren gerçektir (Siu, 2005). Bu nedenle bir kentsel donatı tasarlarken onun sadece işlevsel amaçlara hizmet etmesi düşünülmemeli aynı zamanda mekanları canlandırıcı etkileri açısından da büyük önem taşındığı düşünülerek tasarımlar yapılmalıdır (Guney vd., 1996). Bununla birlikte kolay algılanmaları, çabuk fark edilmeleri yani kent kimliğine anlam kazandıran objeler olmalıdırlar. Böylece kullanıcı için daha etkin ve olumlu yaşanılabilir bir kentsel çevre yaratılmış olur (Güremen, 2011). Dolayısıyla mekânı donatma kavramı ile başlayan tasarım süreci, işlevsel-etkinlik-anlamsal bütünlüğü sağlayarak tamamlanmalıdır. Tüm bu özelliklerin bir arada sağlanması da ancak sürdürülebilirlik yaklaşımıyla mümkün olabilir. Bu çalışmada da amaç, peyzaj mimarlığı eğitiminde sürdürülebilir donatı tasarımı kavramının öğrenme çıktısı olarak öğrenciye kazandırılması, bu bağlamda dersin sürecinin ve ders kapsamında üretilen maketlerin incelenmesidir.

\section{Materyal ve Method}

3.1. Aşama 1

Bu çalışmada materyal olarak, KTÜ Peyzaj Mimarlığı Bölümü 3.yarıyıl derslerinden "Donatı Tasarımı" 
dersinde 2018-2019 güz yarıyılında öğrencilerin farklı etkinlikler için tasarladığı Donatı Maketleri kullanılmıştır. Mekân-donatı bütünlüğünün sürdürülebilirlik ilişkisi içinde kurgulanması peyzaj mimarlığ kapsamında ele alınması gereken önemli bir konu olarak görülmektedir. Peyzaj mimarları; insanların ihtiyaç ve istekleri doğrultusunda çevrenin tasarlanmasıyla kullanıcılara yaşanabilir-sürdürülebilir mekânlar yaratır. Peyzaj mimarlığı disiplininde bu mekânları tasarlarken öncelikle kullanıcı ihtiyaçlarını karşılayan, ergonomik işlevsel tasarımlar sonra da yaratıcılığı üst düzeyde estetik-özgün tasarımlar ön plana çıkmalıdır. Bu nedenle bu ders, öğrencilere uygun etkinlik için uygun ölçü, malzeme, biçime sahip yaratıcı ve buna bağlı olarak sürdürülebilir donatı tasarımı geliştirme anlayışını kazandırmayı amaçlar. Detaylandırılacak olursa bu ders kapsamında öğrenciler, öncelikle donatı elemanları, türleri, ölçüleri, mekânsal kurgusu gibi konularda ve sürdürülebilir tasarım konusunda bilgilendirilirler. Daha sonra dünyadaki tasarlanmış donatı örnekleri mekan-donatı-sürdürülebilirlik ilişkisi açısından incelenir.

Dersin sonraki aşamalarında dersi alan 68 öğrenci gruplara ayrılır, dersin sonunda da her grup seçtiği bir etkinliğe uygun sürdürülebilir tasarım içeren bir donatı maketi yapar (Şekil 1).

$\mathrm{Bu}$ aşamada öğrencilerin farklı etkinlikler için ürettikleri donatı maketleri etkinlik-mekan-sürdürülebilirlik ilişkisi açısından değerlendirilmiştir.

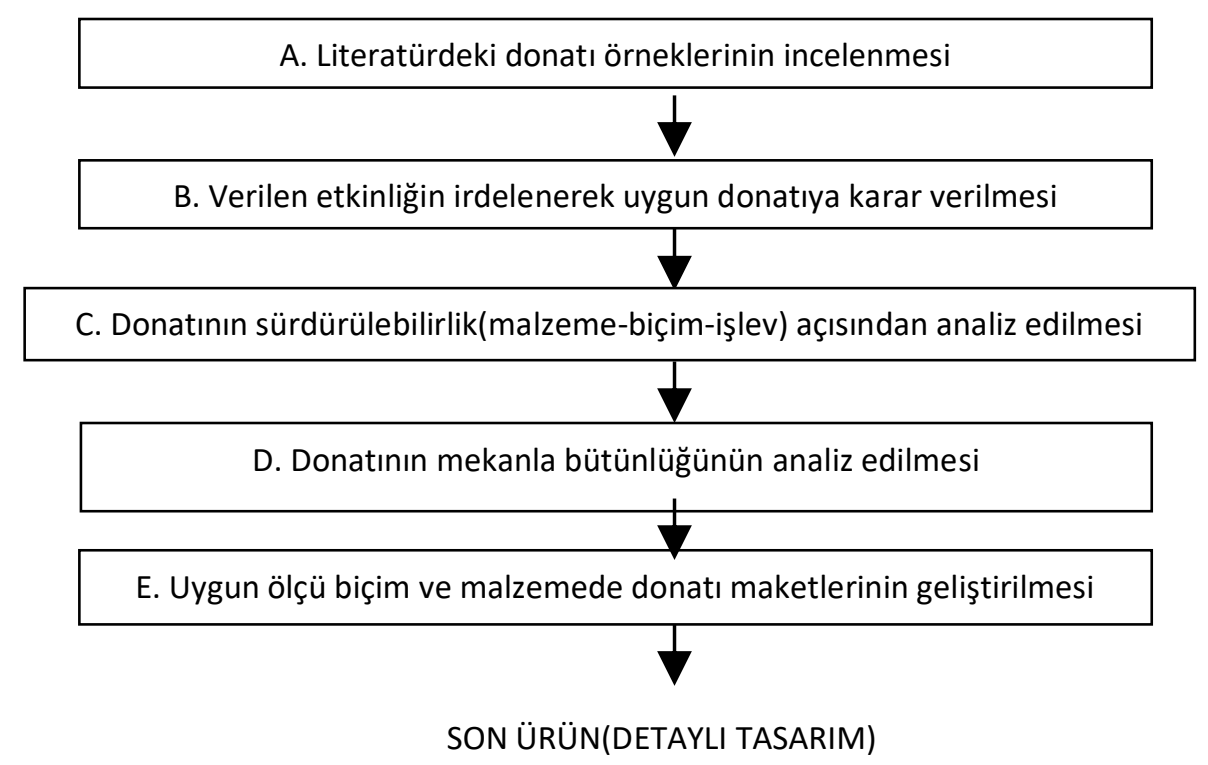

Şekil 1. Donatı Tasarımı dersi kapsamında izlenen süreç

\subsection{Aşama 2. Anket Çalışması}

Dönem sonunda öğrencilere dersin kazanımlarına yönelik anket yapılmıştır. Bu da çalışmanın ikinci kısmını oluşturmaktadır. Anket öğrencilerin donat1-sürdürülebilirlik kavramlarını ilişkilendirme düzeylerinin ne olduğu, sürdürülebilir donatı tasarım sürecini ne kadar öğrendikleri gibi sorulara yanıt bulmak amacıyla yapılmıştır. Ankette öğrencilere;

- Donatıları uygun etkinlik-ölçü-biçim-malzemede tasarlamayı ne kadar öğrendikleri,

- Sürdürülebilirlik kavramını ne kadar öğrendikleri,

- Donatı sürdürülebilirlik ilişkisini kurgulamayı ne kadar öğrendikleri

- Son soruda ise "Donatı Tasarımı" dersini ne kadar öğretici buldukları, 5' li skala verilerek sorulmuş, Puanlama 1 (çok az), 2 (az), 3 (orta), 4 (iyi), 5 (çok iyi) olarak derecelendirilmiştir.

\section{Bulgular ve Tartişma}

\subsection{Aşama 1'in bulguları}

2018 yılında bu ders kapsamında ortaya koyulan öğrenci maketlerinde; farklı etkinliklere yönelik sürdürülebilir donatı çözümleri analiz edilmiştir. Öğrencilerden istedikleri etkinlik türünü seçerek 1/20 ölçeğinde maket boyutunda özgün ve sürdürülebilir donatı tasarlamaları istenmiştir. Yapılan öğrenci maketleri: etkinlik türü-ölçü-biçim-malzeme açısından dolayısıyla sürdürülebilirlik bağlamında Tablo 1' de incelenmiştir. 


\subsection{Aşama 2 'nin Bulguları}

Dersi alan 68 kişiye yapılan anket sonucunda 4.16 ortalamayla en yüksek yüzdeyi soru 1 almıştır. Donatıları uygun etkinlik-ölçü-biçim-malzemede tasarlamayı ne kadar öğrendiklerini araştıran soruda "çok iyi” düzeyde öğrendikleri belirlenmiştir. Sürdürülebilirlik kavramını ne kadar öğrendiklerini araştıran 2. Soruda 3.82 ortalamayla "iyi” düzeyde öğrendikleri belirlenmiştir. Donatı sürdürülebilirlik ilişskisini kurgulamayı ne kadar öğrendiklerini sorgulayan 3. Soruda 3.35 ortalamayla "iyi” düzeyde öğrendikleri belirlenmiştir. Dersin öğrenim düzeyini sorgulayan son soruda 3.82 ortalamayla iyi düzeyde buldukları belirlenmiştir. Şekil 2' de tüm sorulara verilen cevaplara ait \% de grafiği verilmiştir.

Sorulara verilen cevapların farklılıklarının istatistikî açıdan anlamlı olup olmadığının değerlendirilmesi için T-testi yapılmıştır. Donatıları uygun etkinlik-ölçü-biçim-malzemede tasarlamayı çok yüksek düzeyde öğrendikleri yani en yüksek değerleri aldığı belirlenmiştir. Yapılan analizler, verilen yanıtlar arasındaki farklılıkların her soru için anlamlı olduğunu göstermiştir $(\mathrm{p}<0.01)$ : her soru için ortalama ve standart sapma değerleri ile T-testine ilişkin değerler Tablo 2' de verilmiştir.

Dersin öğrenme süreci (etkinlik, ölçü, biçim, ölçü-biçim ilişkisi, malzeme, malzeme-biçim ilişkisi, sürdürülebilir tasarımın öğrenilmesi) ile araştırma soruları arasındaki ilişkiyi belirlemek için korelasyon analizi yapılmıştır (Tablo 3). Bu sonuçlara göre öğrenme sürecinde en etkili faktör soru 1 olmuştur. Tüm faktörler öğrenme sürecinde etkili olmuştur.

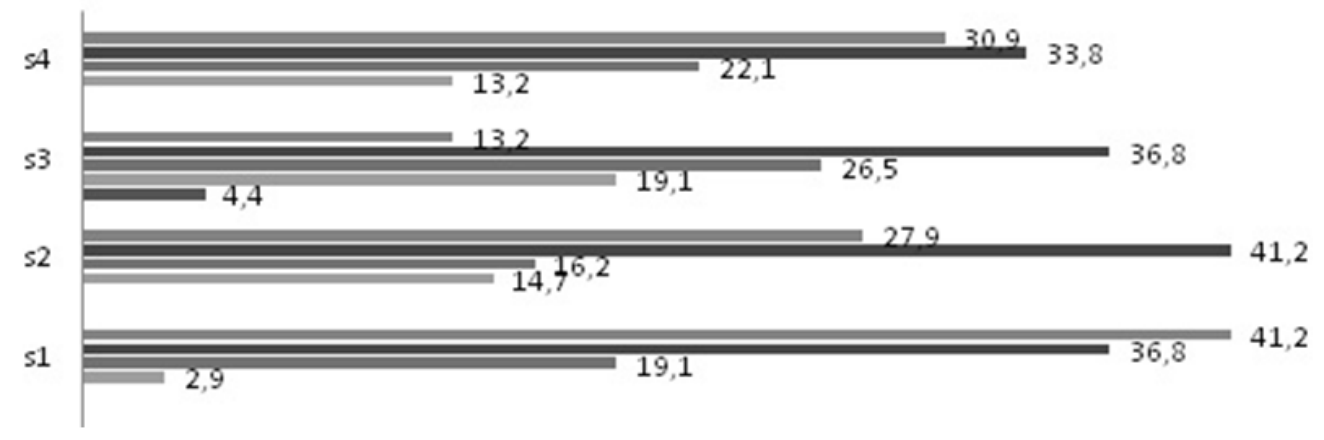

Şekil 2. Tüm sorulara verilen cevaplara ait \% grafiği

\section{Sonuç ve Öneriler}

Sürdürülebilir ve kullanışlı tasarımlar oluşturabilmek için kullanıcı ihtiyaçlarına uygun donatılar tasarlanmalıdır (Siu, 2005; Siu, 2009; Jordan ve Green, 1999; Prudhomme ve ark., 2003; Clarkson vd., 2004). Kentsel mekânlardaki donatı elemanlarının; kullanıcılarının sosyo-kültürel ve estetik açıdan eğitici, işlevsellik açısından yönlendirici ve giderek kent kültürünü olumlu yönde düzenleyici-oluşturucu gibi pek çok önemli görevi bulunmaktadır. Kullanıcılar ve kent açısından farklı bir anlam bütününe ve öneme sahip olan kentsel donatı elemanlarının her biri birer iletişim ve kullanım nesnesi olarak ele alınmalıdır (Aydoğdu, 2017). Bu nedenle kullanıcı beklentilerine cevap verecek uygun ölçü ve biçimde, mekânın kimliğiyle uyumlu malzemeler ile donatıların tasarlanması gerekir. Ortaya çıkan tasarım sürdürülebilir olmalı yani donatının biçim ve işlevi mekân ile uyumlu ve özgün olmalıdır. 
Tablo 1. Öğrenci donatı maketlerinin sürdürülebilirlikaçısından (etkinlik türü-ölçü-biçim-malzeme) incelenmesi
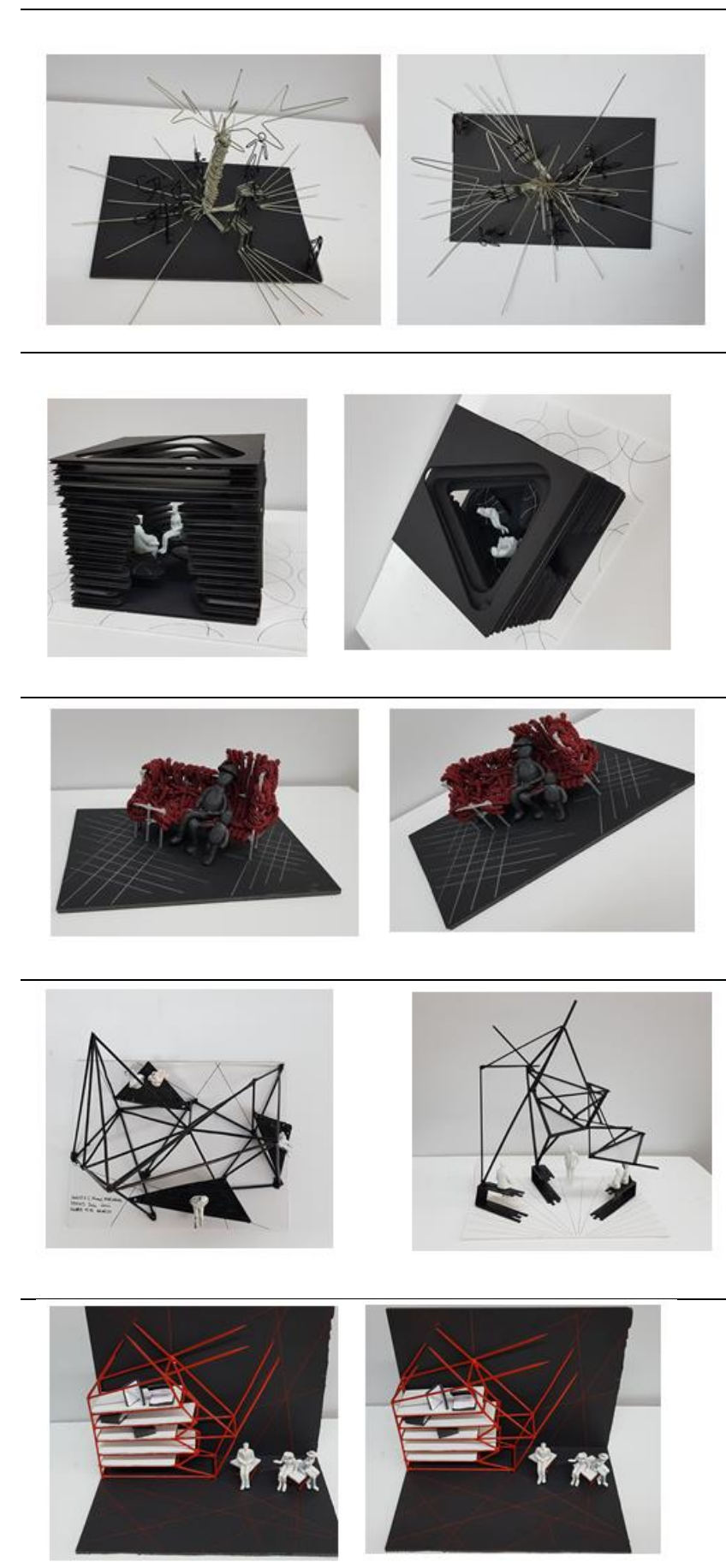

Etkinlik olarak bisiklet park ve oturma dinlenme tasarlanmış. Ölçü olarak park etmeye ve oturmaya uygun olarak ölçülendirilmiştir. Ayrıca plastik obje ve örtü elemanı birarada tasarlanmıştır. Biçim olarak çizgisel süreklilik içeren hatlara sahip bir özgün tasarım yapılmıştır. Metal dayanıklı ve sürdürülebilir bir malzeme olarak tercih edilmiştir.

Etkinlik olarak oturma dinlenme, kitap okuma tasarlanmış. Ölçü olarak oturmaya uygun olarak ölçülendirilmiş̧ir. Ayrıca kamerya örtü elemanı birarada tasarlanmıştır. Biçim olarak küp biçiminde bir özgün tasarım yapılmıştır. Siyah ahşap dayanıklı ve sürdürülebilir bir malzeme olarak tercih edilmiştir.

Etkinlik olarak oturma dinlenme tasarlanmış. Ölçü olarak oturmaya uygun olarak ölçülendirilmiştir. Biçim olarak çizgisel biçimde bir özgün tasarım yapılmıştır. Zemin metal dayanıklı, üzeri ipten sürdürülebilir malzemeler olarak tercih edilmiştir.

Etkinlik olarak oturma dinlenme tasarlanmış. Ölçü olarak oturmaya uygun olarak ölçülendirilmiştir. Ayrıca örtü elemanı oturma ile birarada tasarlanmıştır. Biçim olarak çizgisel, üçgen biçimde bir özgün tasarım yapılmıştır. Siyah ahşap dayanıklı ve sürdürülebilir bir malzeme olarak tercih edilmiştir.

Etkinlik olarak oturma-dinlenme, kütüphane tasarlanmış. Ölçü olarak oturmaya ve kitaplığa uygun olarak ölçülendirilmiştir. Biçim olarak çizgisel, köşeli biçimde bir özgün tasarım yapılmıştır. Kırmızı boyalı ahşap dayanıklı ve sürdürülebilir bir malzeme olarak tercih edilmiştir. 
Tablo 2. Sorulara ait T-testi değerleri

\begin{tabular}{lcrrrrrr}
\hline & & \multicolumn{2}{c}{} & & \multicolumn{2}{c}{$95 \%$ Confidence Interval of the } \\
& & & \multicolumn{2}{c}{ Sig. } & Mean & \multicolumn{2}{c}{ Difference } \\
\cline { 6 - 8 } & $\mathrm{t}$ & df & (2-tailed) & Difference & Lower & \multicolumn{2}{c}{ Upper } \\
\hline S1 & 40,879 & 67 &, 000 & 4,162 & 3,96 & 4,36 \\
\hline S2 & 31,324 & 67 &, 000 & 3,824 & 3,58 & 4,07 \\
\hline S3 & 25,703 & 67 &, 000 & 3,353 & 3,09 & 3,61 \\
\hline S4 & 30,873 & 67 &, 000 & 3,824 & 3,58 & 4,07 \\
\hline
\end{tabular}

Tablo 3. Öğrenme sürecinin araştırma sorularıyla ilişkisi

\begin{tabular}{lccc}
\hline & $\mathrm{S} 1$ & $\mathrm{~S} 2$ & $\mathrm{~S} 3$ \\
\hline $\begin{array}{l}\text { Donatıları } \\
\text { tasarlanmayı ne kadar öğrendiniz }\end{array}$ & - &, $635^{* *}$ &, $713^{* *}$ \\
\hline Sürdürülebilirlik kavramını ne kadar öğrendiniz & & - &, $885^{* *}$ \\
\hline $\begin{array}{l}\text { Donatı sürdürülebilirlik ilişkisini kurgulamayı ne kadar } \\
\text { öğrendiniz }\end{array}$ & & & - \\
\hline Dersin öğreticilik düzeyi &, $869^{* *}$ &, $681^{* *}$ &, $696^{* *}$ \\
\hline **. Correlation is significant at the 0.01 level (2-tailed). & & &
\end{tabular}

Birtakım tasarım ölçütlerine bağlı olarak kullanıcının ihtiyaçlarına yanıt veren mekânlar yaratmayı amaçlayan Peyzaj Mimarlığı disiplini için eğitim sürecinin nasıl olması gerektiği günümüzde hala tartışma konusudur. Bu çalışmada mekân-donatı ilişkisini işlevsel ve estetik açıdan kurgulamayı amaçlayan donatı tasarımı dersinde sürdürülebilir tasarım anlayışının eğitimindeki faydaları ortaya konmuştur. Bu derste;

- Öğrenciler farklı etkinliklere yönelik farklı biçim ve malzemede donatı maketleri yapmıştır.

- Bu eğitim yaklaşımı; tasarım öğrencilerine uygun etkinlik-ölçü-biçim-malzemede tasarlanmayı donatı tasarlamayı anlaşılabilir hale getirmiştir.

- Öğrenciler; Sürdürülebilirlik kavramını iyi düzeyde öğrenmişler, Donatı sürdürülebilirlik ilişkisini kurgulamayla ilgili kendilerini geliştirmişlerdir.

- Öğrencilerin tasarım süreçlerinin gelişimine önemli katkı sağlarken aynı zamanda kullanıcı ihtiyaçlarını karşılayan mekân-donatı bütünlügüüü göz önünde bulunduran sürdürülebilir tasarım anlayışına sahip bilinçli çevresel tasarımcıların yetiştirilmesinde de önemli bir rol oynamaktadır.

Öğrencilerin ilgisi ve bu konuya yönelik alınacak çevre tasarım proje, doğal yapılarla tasarım, malzeme bilgisi vb. Dersler oğrultusunda sürdürülebilir tasarım ile kurulan mekân-donatı ilişkisi arttırılabilir. Böylece tasarımcı-öğrenci, istediği etkinliğe, istediği mekâna uygun, kullanıcı ihtiyaçlarını karşılayan, özgün ve sürdürülebilir donatı tasarımları elde edebilir.

\section{References}

Aydoğdu, H. (2017). Kentsel Donatı Elemanlarını Peyzaj Mimarlığında kullanımı. T.C.Selçuk Üniversitesi Ziraat Fakültesi, Peyzaj Mimarlığı Anabilim Dalı, Konya.

Bourdeau, L. (1999). National Report: S1.ustainable Development and Future of Construction in France. France: Centre Scientıfique Et Technıque Du Bâtıment.

CIB., (1999). Agenda 21 on Sustainable Construction,: CIB Report Publication 237, Rotterdam.

Clarkson, P. John, B. P., Coleman, R., Stubbs, D., Ward, J., Jarrett, J., Lane, R. \& Bound, J. (2004) Design for patient safety: a review of the effectiveness of design in the UK health service. J. Eng. Design, 15(2): 123-140.

Dikmen, Ç.B. (2011). Enerji etkin yapı tasarım ölçütlerinin örneklenmesi. Politeknik Dergisi, 14(2), 121-134. 
Dikmen, Ç. B. \& Gültekin, A. B. (2009). Intelligent Building Concept in Architectural Design Process within Scope of Sustainable Building Design, 19. International Congress of Building and Life: Future of Architecture, Nature, City, Environment, Chamber of Architects, Branch Office of Bursa.

Düzenli T., Alpak E.M., Çiğdem A. \& Tarakci Eren E. (2018a). The Effect of Studios on Learning in Design Education, Journal of History Culture and Art Research, 7:191-204.

Düzenli T., Alpak E.M. \& Tarakci Eren E. (2018b). Open Space In The Context Of Spatial Organization, International Journal of Eurasia Social Sciences , 9:1188-1201.

Düzenli T., Mumcu S. \& Çiğdem A., (2018c). Peyzaj Mimarlığı Eğitiminde Oturma Donatısı Tasarımı: Ktu Peyzaj Mimarlığı Bölümü Örneğinde İncelenmesi, NWSA Social Sciences, 13:126-134.

Düzenli T., Yilmaz S. \& Alpak E.M., (2017). The Effects of Model Making on Design and Learning in Landscape Architecture Education, Eurasian Journal of Educational Research, 17:121-134.

Ertaş, D. G. (2007). Yapısal Özelliklerin Endüstri Ürünleri Tasarımına Etkileri. İstanbul Teknik Üniversitesi Fen Bilimleri Enstitüsü Doktora Tezi, Endüstri Ürünleri Anabilim Dalı, İstanbul, 197.

Güney, A., Erdem, Ü., Zafer, B., \& Hepcan, Ş. (1996). Peyzaj Konstrüksiyonu (Donatı Elemanları). İzmir: Ege Üniversitesi Ziraat Fakültesi Yayınları.

Güremen, L. (2011). Kent Kimliği ve Estetiği Yönüyle Kentsel Donatı Elemanlarının Amasya Kenti Özelinde Araştırılması. E-Journal of New World Sciences Academy, 6 (2), 254-291.

Jordan Patric,k W. \& Green William, S (1999). Human Factors in Product Design: Current Practice and Future Trends. Taylor and Francis, London.

Kumbaracıbaşı, C. (1991). Kent, Estetik, Ankara, 2000'li Yıllar İçin Ankara Kenti’nin Açık ve Yeşil Alan Sistemi Ne Olmalıdır?. Ankara Büyükşehir Belediyesi \& Peyzaj Mimarlığı Derneği Sempozyum Bildirileri Ortak Yayını, 29-31 Mayıs, Ankara, 65-67.

Kurdoğlu, B. Ç., Bayramoğlu, E. \& Konakoğlu, S. S. K. (2016). Kampüslerde Yaya ve Bisiklet Yollarına Uygun Sürdürülebilir Donatı Tasarım Kriterleri. Uluslararası Bilimsel Araştırmalar Dergisi (IBAD), 3(2), 493-502.

Prudhomme G, Zwolinshi P., \& Brissaud D (2003) Integrating into the design process the needs of those involved in the product life-cycle. Journal of Engineering Design, 13(3): 333-353.

Siu, K. \& Wai, M. (2007). Guerrilla wars in everyday public spaces: reflections and inspirations for designers, International Journal of Design, 1(1): 37-56.

Siu, K. \& Wai, M. (2009) Public design for changing urban needs, Korean Society of Design Science, Seul, , 3085-3093.

Şatır, S. (2015). Sürdürülebilir Kentsel Mekanlar ve Kent Mobilyaları. Tasarım+ Kuram Dergisi, 11(19), 1-18.

WGSC, (2004). Working Group for Sustainable Construction, Working Group Sustainable Construction Methods and Techniques Final Report.

Yeang, K.. (1999). The Green Skyscraper: The Basis for Designing Sustainable Intensive Buildings, Munich. 